\title{
Monitoring aquatic plants: An evaluation of hydroacoustic, on-site digitising and airborne remote sensing techniques
}

\author{
Jerom R. Stocks ${ }^{1, *}$, Michael P. Rodgers ${ }^{1}$, Joe B. Pera ${ }^{2,3}$ and Dean M. Gilligan ${ }^{1}$ \\ ${ }^{1}$ New South Wales Department of Primary Industries, New South Wales Fisheries, Batemans Bay Fisheries Centre, PO Box 17, \\ 2536 Batemans Bay, NSW, Australia \\ ${ }^{2}$ WaterNSW, PO Box 398, 2124 Parramatta, NSW, Australia \\ ${ }^{3}$ University of Technology Sydney, PO Box 123, 2007 Broadway, NSW, Australia
}

\section{Received: 7 February 2019 / Accepted: 26 April 2019}

\begin{abstract}
Aquatic macrophytes are often monitored to detect change in ecosystem function and state, as well as assessing the effectiveness of invasive aquatic plant management. This study compares seven methodologies to monitor the distribution and abundances of aquatic macrophytes. Four line transect methodologies and three spatial mapping techniques were employed in parallel over a broad turbidity gradient in two lentic habitats of south-eastern Australia. The methodologies examined included hydroacoustic surveys, on-site digitising, and digitisation of airborne remote sensing imagery. Variation in estimates of macrophyte coverage were observed between methodologies. Consistency in the collection and interpretation of data was greatest for the line transect methodologies and the digitisation of satellite imagery. Duel-frequency identification sonar proved to be an effective novel hydroacoustic technique to monitor macrophyte abundances over broad spatial scales. Single beam sonar transects was also an objective, repeatable and scalable methodology. Videography and on-site handheld PDA mapping were of limited utility due to restrictions imposed by turbidity. The utility of sidescan sonar could be improved when used in conjunction with on-site handheld PDA mapping. This study outlines important considerations when selecting a methodology to monitor macrophyte distribution and abundance. Results indicate that no one specific method can be employed across all macrophyte monitoring studies. The method or combination of methods employed during macrophyte monitoring studies is dependent upon the study objectives, budget and environmental conditions of the study site.
\end{abstract}

Keywords: aquatic macrophyte / aquatic plant / hydroacoustic mapping / aquatic habitat mapping / macrophyte monitoring / DIDSON / sidescan sonar

Résumé - Suivi des plantes aquatiques: une évaluation des techniques hydroacoustiques, de numérisation sur site et de télédétection aérienne. Les macrophytes aquatiques font souvent l'objet d'un suivi pour déceler les changements dans le fonctionnement et l'état de l'écosystème, et pour évaluer l'efficacité de la gestion des plantes aquatiques envahissantes. Cette étude compare sept méthodologies pour surveiller la distribution et l'abondance des macrophytes aquatiques. Quatre méthodes de transects linéaires et trois techniques de cartographie spatiale ont été employées en parallèle sur un large gradient de turbidité dans deux habitats lentiques du sud-est de l'Australie. Les méthodologies examinées comprenaient les levés hydroacoustiques, la numérisation sur place et la numérisation de l'imagerie de télédétection aéroportée. Des variations dans les estimations de la couverture des macrophytes ont été observées entre les méthodologies. L'uniformité dans la collecte et l'interprétation des données était la plus grande pour les méthodes de transects linéaires et la numérisation de l'imagerie par satellite. Le sonar d'identification à double fréquence s'est avéré être une technique hydroacoustique novatrice efficace pour surveiller l'abondance des macrophytes sur de vastes échelles spatiales. Les transects sonar à faisceau unique étaient également une méthode objective, répétable et évolutive. La vidéographie et la cartographie à l'aide d'un assistant numérique personnel sur place étaient d'une utilité limitée en raison des restrictions imposées par la

\footnotetext{
*Corresponding author: jerom.stocks@dpi.nsw.gov.au
} 
turbidité. L'utilité du sonar à balayage latéral pourrait être améliorée s'il était utilisé en conjonction avec la cartographie PDA portable sur site. Cette étude souligne des considérations importantes dans le choix d'une méthodologie de surveillance de la distribution et de l'abondance des macrophytes. Les résultats indiquent qu'aucune méthode spécifique ne peut être utilisée pour toutes les études de surveillance des macrophytes. La méthode ou la combinaison de méthodes employées pendant les études de surveillance des macrophytes dépend des objectifs de l'étude, du budget et des conditions environnementales du site à l'étude.

Mots clés : macrophyte / plante aquatique / cartographie hydroacoustique / DIDSON / sonar à balayage latéral

\section{Introduction}

Aquatic macrophyte communities play an important role in freshwater aquatic ecosystems by: influencing nutrient cycling and trophodynamics; forming an important structural habitat component; influence fish productivity; altering the geophysical characteristics of a systems, and; influencing water quality variables such as turbidity and dissolved oxygen (Caraco and Cole, 2002; Genkai-Kato and Carpenter, 2005; Choi et al., 2014). However, in high abundances invasive aquatic plants can be detrimental to ecosystem function and the public utility value of water resources (Kelly and Hawes, 2005; Zhang and Boyle, 2010). The spatial and temporal extent of aquatic macrophyte communities are often dynamic, responding to change in variables such as hydrology, water temperature, nutrient levels, turbidity, grazing and implementation of control measures (Lacoul and Freedman, 2006; Szoszkiewicz et al., 2014; Yu et al., 2016). Consequently, aquatic macrophytes are monitored to detect change in ecosystem function and state, as well as assessing the effectiveness of invasive aquatic plant management (Netherland and Jones, 2015).

Various techniques are available to measure and analyse quantitative and qualitative attributes of aquatic macrophytes, such attributes include: species composition, spatial distribution, depth distribution, density, biomass and plant height (Johnson and Newman, 2011). Sabol et al. (2002) categorised methods into three broad groups:

- physical;

- on-water remote;

- off-water remote.

Physical methodologies generally involving quadrat or point transect application of rake tosses, diver quadrats and bathyscopes (Madsen, 1999; Havens et al., 2002; Skogerboe et al., 2008; Johnson and Newman, 2011). These can provide both quantitative and qualitative data, but are labour intensive and more appropriate for small spatial extents.

On-water remote methodologies generally involve the collection of data from a vessel using hydroacoustic sensing equipment or towed video cameras. Hydroacoustic sensing equipment may include single beam, multi beam and sidescan sonar systems (Bickers, 2003; Kruss et al., 2009; Kaeser and Litts, 2010; Christia et al., 2014; Netherland and Jones, 2015; Radomski and Holbrook, 2015; Valley et al., 2015). Single beam sonar uses acoustic signals that travel through submerged vegetation canopies on the way to bottom sediments. The substratum typically registers a sharper echo-return than the aquatic vegetation, allowing the presence/absence of aquatic macrophytes to be determined. Georeferenced single beam hydroacoustic data can be interpreted manually or automated processing is offered through multiple cloud-based software platforms (Radomski and Holbrook, 2015; Valley et al., 2015). Sidescan sonar is an acoustic imaging process that provides wide-area, highresolution acoustic images. Georeferenced acoustic data can then be digitised in a GIS to provide spatial information on macrophyte communities. The increasing availability of reliable, low cost recording sonar units has made single beam and sidescan sonar data collection possible under most monitoring program budgets.

Towed optical video systems can often provide easily interpretable images for qualitative and quantitative assessment; however, the field of view is highly dependent upon turbidity and data processing can be labour intensive. Duelfrequency Identification Sonar (DIDSON, Sound Metrics, Bellevue, WA, USA) is an acoustic camera providing video imagery in turbid or dark water where optical systems are ineffective (SoundMetrics, 2008). The application of DIDSON to fisheries research includes observations of fish behaviour, estimate of fish abundances and fish size (Moursund et al., 2003; Holmes et al., 2006; Boswell et al., 2008; Boys et al., 2013; Langkau, 2018). The use of DIDSON to monitor the distribution and abundance of macrophyte communities is a novel hydroacoustic technique that has been rarely assessed (Mizuno et al., 2018). Mizuno et al. (2018) validated the use of DIDSON to estimate macrophyte biomass in small 3dimensional quadrats, however, the application of DIDSON transects to monitor macrophyte coverage over larger spatial scales is a novel technique.

Off-water remote methodologies involve the collection and interpretation of airborne or satellite derived remote sensing imagery (Everitt et al., 1999; Creese et al., 2009). Such techniques have significantly improved survey speeds and allow monitoring over large spatial scales; however, are limited by resolution, water penetration and cloud obstruction. Processing of imagery generally involves digitising macrophyte beds and can be done manually or automated through software platforms (CMAP, 2018). These software platforms use algorithms that classify imagery based on the unique reflectance properties of aquatic vegetation.

The macrophyte monitoring method employed will be dependent upon the data requirements of the study. In some studies, quantitative measures of abundance and density may be of importance, whereas in other instances further information on qualitative attributes such as species composition may be required. The scale and spatial extent of monitoring will also influence the methodology employed (Johnson and Newman, 2011). However, when selecting a methodology, considerations common to all studies include accuracy, precision, sensitivity to tubidity and cost-effectiveness of an objective repeatable procedure. 
The primary objective of this study was to assess and compare a selection of current methods available to monitor the percentage area cover (PAC) of macrophytes in aquatic habitats with varying turbidities. More specifically, this study aimed to:

- assess conformity between methodologies;

- assess variation in data collection and interpretation between operators;

- assess time and cost of equipment, data collection and processing;

- assess pros/cons and limitations of each method.

This was achieved by comparing seven methodologies employed in parallel over a broad turbidity gradient in two lentic habitats. The methodologies examined included four line transect methodologies: $200 \mathrm{kHz}$ sonar, $800 \mathrm{kHz}$ downscan sonar, DIDSON \& optical videography; and three spatial mapping techniques: $800 \mathrm{kHz}$ sidescan sonar, handheld PDA Trimble mapping and satellite imagery.

\section{Materials and methods}

\subsection{Study location}

Macrophyte community assessments were conducted in two lentic habitats of South-Eastern Australia during the autumn of 2017. The study sites included a small urban lake (Landsdowne Lake), and Green Bay within Prospect Reservoir; each having an area of approximately 3 hectares. Study sites were chosen to incorporate a range of water depths and turbidities. Landsdowne Lake had the highest turbidity of $0.58 \mathrm{~m}$ secchi depth, with a maximum depth of $4 \mathrm{~m}$. Green Bay within Prospect Reservoir had the lowest turbidity of $1.64 \mathrm{~m}$ secchi depth and a maximum depth of $6 \mathrm{~m}$.

\section{$2.2200 \mathrm{kHz}$ sonar \& $800 \mathrm{kHz}$ downscan sonar}

Hydroacoustic georeferenced line transect data of aquatic macrophyte presence/absence was collected with a Lowrance HDS7 Gen3 GPS integrated echo-sounder with a total-scan transducer. At each site, sonar recordings were collected from three 500-m transects spaced at $5 \mathrm{~m}$ intervals from the bank. A track was recorded during each transect and displayed on the Lowrance head-unit in 'split screen mode' to assist with transect spacing. Mapping was conducting from a flat bottom punt with a transom-mounted transducer. Sonar logs were recorded at a consistent speed of 1 knot using an outboard petrol engine. The sonar recordings were logged at a rate of 15 to 20 data signals. ${ }^{-1}$ at $200 \mathrm{kHz}$ with a 208-beam angle; $800 \mathrm{kHz}$ downscan imagery was simultaneously recorded. The sounder display was continually monitored to ensure the unit was detecting bottom and producing a clear reading. Transects where the sounder 'lost' bottom identification or the soundings were not clear were repeated.

Manual processing of the georeferenced $200 \mathrm{kHz}$ sonar and $800 \mathrm{kHz}$ downscan sonar was performed in 'ReefMaster Sonar Viewer' version 1.0.36.0 software package (https://reefmaster. com.au/). Lowrance sonar .sl3 files containing both the $200 \mathrm{kHz}$ sonar and $800 \mathrm{kHz}$ downscan sonar recordings were analysed independently to prevent bias. Start and end times for macrophyte beds and bare substratum were recorded along the

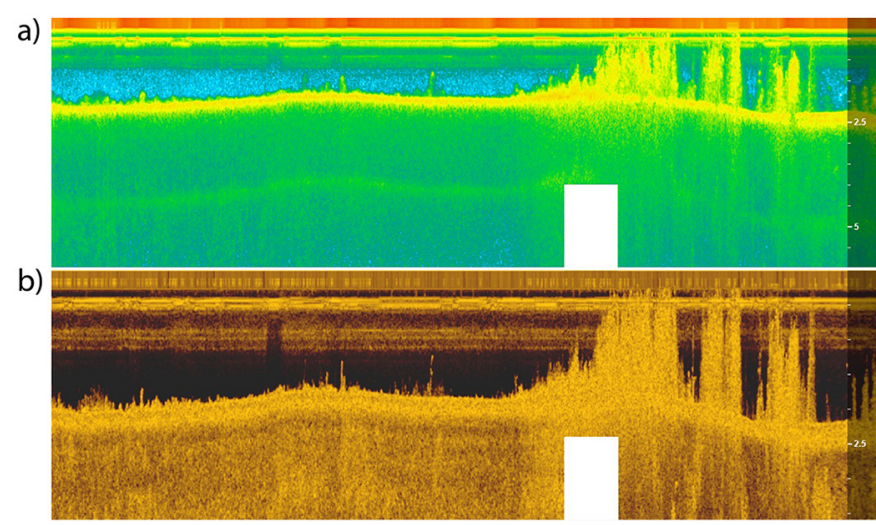

Fig. 1. a) $200 \mathrm{kHz}$ sonar, and; b) $800 \mathrm{kHz}$ downscan imagery collected using a Lowrance HDS Gen3 echosounder displayed in 'ReefMaster Sonar Viewer' illustrating macrophyte presence along a lake transect.

transect. Macrophyte beds were easily distinguishable from bare substratum (Fig. 1).

\section{$2.3800 \mathrm{kHz}$ sidescan sonar}

During each transect, sidescan imagery was simultaneously recorded using the same Lowrance HDS7 Gen3 GPS integrated echosounder with total-scan transducer. Sidescan sonar imagery was collected at $800 \mathrm{kHz}$ with a range of 2 3 times the water depth. The outermost transect was conducted in a direction to ensure the transom mounted sidescan transducer had a clear view towards the bank, without the outboard motor leg blocking the sonar signal.

SonarTRX Pro (http://www.sonartrx.com/) was used to convert Lowrance .sl3 sidescan sonar files to georeferenced. png image tiles compatible for GIS ArcMap processing. Macrophyte beds distinguishable from the sidescan imagery were digitised into polygons and the total macrophyte surface area calculated (Fig. 2); the identification of species was not possible from sidescan imagery alone. The water column was eliminated from the sidescan imagery to ensure true spatial scale when digitising the macrophyte beds.

\subsection{DIDSON \& optical videography}

During each transect a gunnel mounted forward facing DIDSON and GoPro video camera collected imagery of the aquatic bathymetry. The DIDSON and GoPro were submerged $20 \mathrm{~cm}$ below the water surface and aimed downwards at an angle of between $20-40^{\circ}$ from horizontal depending upon water depth (a larger angle was used during deeper transects). GoPro and DIDSON recordings were synchronised with the sonar recordings allowing for standardization when comparing each of the methods. The GoPro footage was recorded in wideangle mode at $920 \times 1080$ pixels and 60 FPS. The DIDSON data was collected at $1.8 \mathrm{MHz}$ (high-frequency mode) with a window start of $2.5 \mathrm{~m}$, maximum range of $12 \mathrm{~m}$ and frame rate of 7 FPS. The DIDSON and GoPro imagery was analysed using a line transect methodology. The time point along the transect at the boundary between bare bottom, macrophyte 
a)

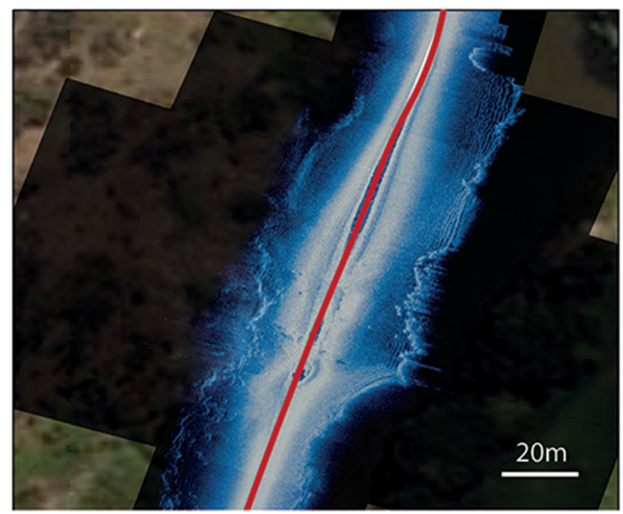

b)

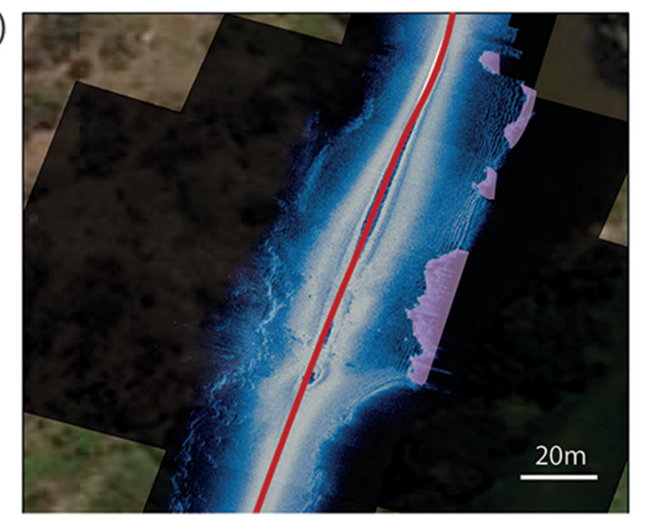

Fig. 2. a) $800 \mathrm{kHz}$ sidescan imagery collected from a single pass transect (red line) of a narrow lake section using a Lowrance HDS Gen3 echosounder, and; b) digitised $800 \mathrm{kHz}$ sidescan imagery illustrating a macrophyte beds (pink polygons) on the right shore of the lake separated by rippled sandy substrate.

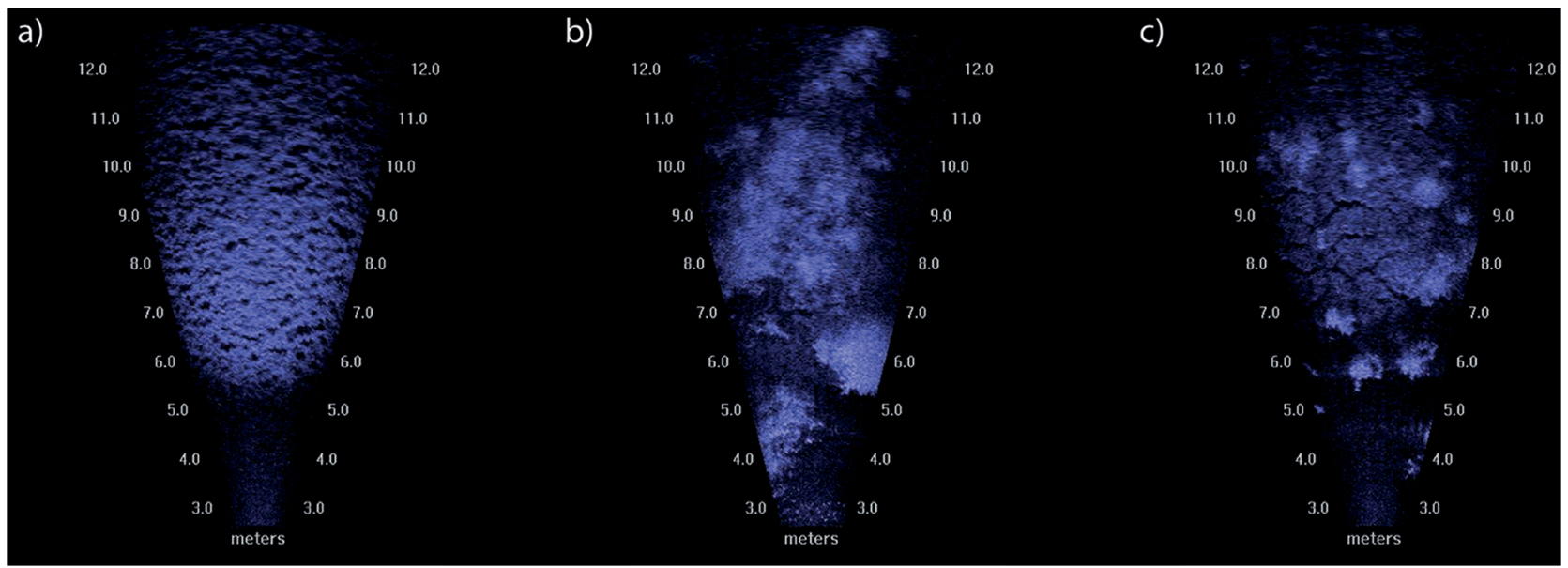

Fig. 3. Freeze-frame of Duel-Frequency Identification Sonar (DIDSON) recordings in $2 \mathrm{~m}$ depth illustrating: a) bare sediment substrate; b) dense macrophyte coverage, and; c) sparse macrophyte coverage over cracked clay substrate.

presence and 'unknown substrate' was recorded. From the DIDSON footage the presence/absence of macrophytes was categorised at the $7 \mathrm{~m}$ focal point (Fig. 3) and between 0.58 $1.64 \mathrm{~m}$ for the GoPro footage, depending upon turbidity. The presence of macrophytes from both the DIDSON and GoPro footage was further categorized as either sparse $(<50 \%$ macrophyte coverage in the horizontal field of view) or dense ( $>50 \%$ macrophyte coverage in the horizontal field of view). A category of 'Unknown' was assigned when the presence/ absence of macrophyte could not be determined from the recorded footage. It was not possible to identify the species of macrophyte from DIDSON footage, however, the macrophyte species was recorded from GoPro footage where possible.

\subsection{Handheld PDA Trimble mapping}

Spatial distribution of aquatic macrophytes was mapped by two independent field teams from a boat using a handheld differential GPS PDA Trimble unit (Trimble Nomad, Sunnyvale, CA) with TerraSync data acquisition software.
Prior to field mapping, the PDA Trimble was loaded with a base map of the study site. Macrophyte mapping was conducted from the shore to the outermost transect. The spatial distribution of macrophytes was mapped by creating polygons around macrophyte beds. Spatial data was recorded in either of two formats, position-dependent or positionindependent, depending on the ability to maneuver the boat around the macrophyte bed. Macrophytes were recorded to genus level using Sainty and Jacobs (2003). All data was uploaded into a GIS (ArcGIS 10.3.1, ESRI Inc.) for processing and the total area of the macrophyte polygons calculated.

\subsection{Satellite imagery}

Nearmap satellite imagery collected within 2 weeks of field sampling was attained for each study site at a $0.2-\mathrm{m}$ pixel resolution. Macrophyte beds were digitised and macrophyte surface area calculated from the cloud-free georeferenced satellite imagery within ESRI ArcGIS. Classification of macrophyte species was not possible from the satellite 
Table 1. Comparison of macrophyte percentage area coverage derived from the 3 spatial monitoring techniques assessed over the same spatial extent within Prospect Reservoir and Landsdowne Lake. Handheld PDA Trimble mapping data was collected by two trained independent field teams; sidescan and satellite imagery was digitised by two trained independent technicians.

\begin{tabular}{llllll}
\hline & \multicolumn{2}{l}{ Prospect Reservoir } & & \multicolumn{2}{l}{ Landsdowne Lake } \\
\cline { 2 - 3 } & Team/ technician I (\%) & Team/ technician II (\%) & & Team/technician I (\%) & Team/technician II (\%) \\
\hline Digitised sidescan imagery & 24.21 & 37.14 & 15.31 & 12.16 \\
PDA Trimble mapping & 18.62 & 21.98 & 8.02 & 13.80 \\
Digitised satellite imagery & 53.31 & 45.99 & 18.12 & 17.48 \\
\hline
\end{tabular}

imagery alone, all macrophyte species were therefore digitised with no distinction made between species and the total area of the macrophyte polygons were summed.

\subsection{Analytical methodology}

To compare estimates of macrophyte abundance between each simultaneously recorded line transect methodology $(200 \mathrm{kHz}$ sonar, $800 \mathrm{kHz}$ downscan sonar, DIDSON and GoPro), the proportion of time that macrophytes occupied each transect was calculated as a percentage of the total transect time. To allow comparisons between methods, periods throughout a transect that were categorized as 'unknown' for any of the methods were removed from the time series of all methods. The percentage of each transect classified as 'unknown' was also calculated individually for each of the 4 transect methodologies. This procedure was repeated for data sets processed by each of the two data interpreters individually.

A nested Analysis of Variance (ANOVA) was used to compare macrophyte percentage cover estimates between the four line transect methodologies. All data were arcsin transformed prior to analysis. ANOVA was also used to compare the mean percentage of transects classified as 'unknown' macrophyte presence/absence between the four line transect methodologies.

Macrophyte PAC was calculated from each of the three spatial mapping methodologies (sidescan, Handheld PDA Trimble mapping \& satellite imagery). Handheld DPA Trimble mapping data was collected by two trained independent field teams; sidescan and satellite imagery was digitised by two trained independent technicians.

\section{Results}

The nested ANOVA comparing estimates of macrophyte coverage between each line transect methodology indicated a significant difference between methods $\left(F_{3,39}=4.04 ; P\right.$ $<0.05)$. Estimates of macrophyte coverage collected using DIDSON were significantly $(P<0.05)$ lower than that of all other methods $(\mathrm{DIDSON}=74.59 \% \pm 4.77 \mathrm{~S}$.E, optical videography $=80.45 \% \pm 5.16$ S.E,$\quad 800 \mathrm{kHz}$ downscan $=82.45 \% \pm$ 4.78 S.E, $200 \mathrm{kHz}$ sonar $=81.53 \% \pm 4.89$ S.E). There was no significant difference in the macrophyte coverage estimates between observers for each of the line transect methodologies $\left(F_{3,52}=0.38 ; P>0.05\right)$. However, substantial differences in macrophyte PAC were identified between observers for two of the three spatial mapping techniques, sidescan \& PDA Trimble mapping; there was minimal variation in PAC estimates between observers digitising satellite imagery (Tab. 1).
For the sonar and downscan methods, no proportion of the transects were classified as 'unknown' macrophyte presence/ absence. The average percentage of transects that were categorised as 'unknown' was significantly greater for videography when compared against DIDSON $\left(F_{1,55}=34.66 ; \quad P<0.001\right)$. For videography transects a significantly greater proportion of transects were classified as 'unknown' in the more turbid Lansdown Lake (Prospect $=$ $37.67 \%$ 'unknown' \pm 5.18 S.E; Landsdowne $=73.30 \%$ 'unknown' \pm 2.79 S.E; $\left.F_{1,55}=34.66 ; P<0.001\right)$. Of the line transect methods, DIDSON had the second greatest proportion of transects categorized as 'unknown', making up $6.96 \% \pm 2.13$ S.E and $11.69 \% \pm 2.93$ S.E for Prospect and Landsdowne Lake respectively. There was no significant difference in the proportion of a DIDSON transect classified as 'unknown' between observers $\left(F_{1,52}=0.02 ; P>0.05\right)$.

The PAC measure for macrophytes varied considerably between spatial mapping techniques (Tab. 1). Within both reservoirs, digitised satellite imagery resulted in the highest estimates of PAC, whereas PDA Trimble mapping had the lowest (Tab. 1). The mean percentage difference of macrophyte PAC estimates between digitised satellite imagery and PDA Trimble mapping was $48.52 \% \pm 9.55$ S.E. Large variation in PAC was observed between field teams collecting handheld PDA Trimble mapping data (mean \% difference $=28.57 \% \pm 13.29$ S.E.) and between technicians digitising sidescan imagery (mean $\%$ difference $=27.71 \% \pm$ 7.13 S.E.). The least variation in PAC was observed between technicians digitising satellite imagery data (mean \% difference $=8.66 \% \pm 5.08$ S.E.).

\section{Discussion}

Variation in estimates of macrophyte coverage were observed between methodologies. Consistency in the collection and interpretation of data was greatest for the line transect methodologies and the digitisation of satellite imagery. DuelFrequency Identification Sonar proved to be an effective novel hydroacoustic technique to monitor macrophyte abundances over broad spatial scales, independent of water turbidity. Single beam sonar transects was also an objective, repeatable and scalable methodology under a range of turbidities; whereas videography and on-site handheld PDA mapping were of limited utility due to restrictions imposed by turbidity.

There was no significant difference in the macrophyte coverage estimates between observer interpretations for each of the line transect methodologies. However, substantial differences in macrophyte surface area coverage were 
identified between observers for two of the three spatial mapping techniques, sidescan and PDA Trimble mapping; there was minimal variation in PAC estimates between observers digitising satellite imagery. Consistency in data interpretation and collection is important for monitoring studies in order to maximize power to detect change. While strict standardized protocols can reduce measurement error, some methods have more inherent potential for variation, as illustrated by the handheld PDA Trimble mapping and sidescan techniques.

Hydroacoustic macrophyte monitoring techniques can be applied and analysed independent of turbidity, proving to be advantageous over optical techniques. When using the $200 \mathrm{kHz}$ sonar and $800 \mathrm{kHz}$ downscan methods, no proportion of transects were classified as 'unknown' macrophyte presence/absence within each of the study lakes. Similarly, only a small proportion of DIDSON footage was classified as 'unknown'; this was due to either debris obscuring of the lens or failure to adjust the DIDSON recording angle to account for changes in water depth. In contrast a high proportion of optical video footage was classified as 'unknown' from both lakes, significantly reducing the utility of optical videography as a means to effectively monitor macrophyte coverage.

Field data collected using sidescan sonar is comparatively quicker than all other hydroacoustic techniques assessed, as large areas $(40+m$ range: dependent upon water depth, sonar transmission frequency and required image quality) can be mapped from a single pass transect. However, in some instances identifying and digitising macrophyte beds from the sidescan imagery can be subjective and difficult without ground truthing data as illustrated by the large variation between technician interpretations when digitising sidescan imagery. The importance of ground truthing has been highlighted by others using sidescan sonar for aquatic habitat mapping (Bickers, 2003; Kaeser et al., 2013). Sidescan imagery can also be restricted when the water column is fully occupied by dense macrophyte beds (Kaeser and Litts, 2013). In some instances within this study, the sidescan sonar did not penetrate dense macrophytes canopies, and thus only provided information on the boundary of the near-side edge rather than the full spatial extent of the macrophyte bed (Fig. 2). However, when used in conjunction with handheld PDA Trimble mapping the two methods are complementary. Sidescan provides accurate turbidity independent spatial data on the deeper boundary edge of macrophyte beds and the turbidity sensitive handheld PDA Trimble mapping technique provides information on species composition and on the shallow boundary extent of macrophyte beds.

Both $800 \mathrm{kHz}$ downscan and $200 \mathrm{kHz}$ sonar provide an objective, repeatable and scalable methodology to monitor macrophyte communities. Both are effective quantitative methods unbiased by turbidity; however, neither provides qualitative data such as species composition when used in isolation. Where species composition is of interest, qualitative investigations by divers or alternative biological sampling methods are required. The $800 \mathrm{kHz}$ Downscan sonar provided more structural detail to aid in the distinction between fallen timber and macrophyte beds, whereas the $200-\mathrm{kHz}$ sonar showed better distinction of the boundary between hard substrates and the softer echo-return of macrophytes (Fig. 2). Given that most sonar units can record both $800 \mathrm{kHz}$ downscan and $200 \mathrm{kHz}$ sonar simultaneously, viewing both frequencies in unison can aid in data interpretation. Both standard sonar and downscan sonar provide information on the depth distribution and proportion of the water column occupied by macrophytes (Kruss et al., 2009; Valley et al., 2015). However, as with all transect methodologies collected from a propeller driven vessel, fouling of the propeller when motoring through dense macrophytes can be problematic. Furthermore, in dense surface-to-substrate macrophyte beds, the sounder unit can lose 'bottom detection' resulting in data gaps throughout a transect.

Manual processing of $200 \mathrm{kHz}$ sonar and $800 \mathrm{kHz}$ downscan sonar recordings within the 'ReefMaster Sonar Viewer' software package was substantially less labour intensive than applying line/point transect analyses to DIDSON and optical videography; with little variation in interpretation between observers for the former. Software platforms are available that automate $200 \mathrm{kHz}$ sonar and GPS signal processing and create GIS data layers of macrophyte depth distribution, PAC and plant height; completely eliminating any biases introduced by observer interpretation (Valley et al., 2015). Although not examined in this study, other scientific echosounders and automated data processing software are available for aquatic habitat mapping that can simultaneously provide information on fish distribution and biomass (BioSonics, 2019).

For both DIDSON and videography, data processing can be labour intensive, as the footage from each transect has to be viewed and a point/line transect analysis applied to obtain quantitative data. This will likely not be cost effective over large spatial scales. Qualitative data such as species composition can be obtained from video footage, however can be difficult to determine from DIDSON footage without ground truthing data. However, studies have used a modified DIDSON apparatus and image processing technology to generate 3D imaging for aquatic plant species identification (Mizuno et al., 2013; Xu et al., 2013; Mizuno and Asada, 2014). Optical videography proved to be of limited utility in the two-study lakes due to the limitations imposed by turbidity. In this study, the camera was mounted from the boat gunnel at a consistent depth of $20 \mathrm{~cm}$ below the surface. A towed optical camera with an adjustable depth or remote underwater vehicle mounted camera would reduce the proportion of the transect classified as 'unknown' in deeper waters where macrophytes were not visible. The DIDSON did however provide clear footage of the substratum, allowing easy distinction of macrophyte beds independent of turbidity at transect depths between 0.3 to $5 \mathrm{~m}$ (Fig. 3). Monitoring in depths of $>15 \mathrm{~m}$ would be achievable, however the area of insonified substrate is reduced in greater water depths as the mounting angle is increased to maintain sonar contact with the substrate. However, the price of purchasing a DIDSON, with a current market value of $>\$ 90,000$ AUD, would reduce the practicality of employing this method under most monitoring budgets, eliminating this technique as a 'cost-effective' methodology.

As a standalone technique, handheld PDA Trimble mapping did not prove to be an objective, repeatable methodology. Considerable divergence in onsite data collection was observed between field teams. The method does provide both qualitative and quantitative data, however it is significantly limited by turbidity and surface chop that reduce visibility. The method does however provide georeferenced 
J.R. Stocks et al.: Knowl. Manag. Aquat. Ecosyst. 2019, 420, 27

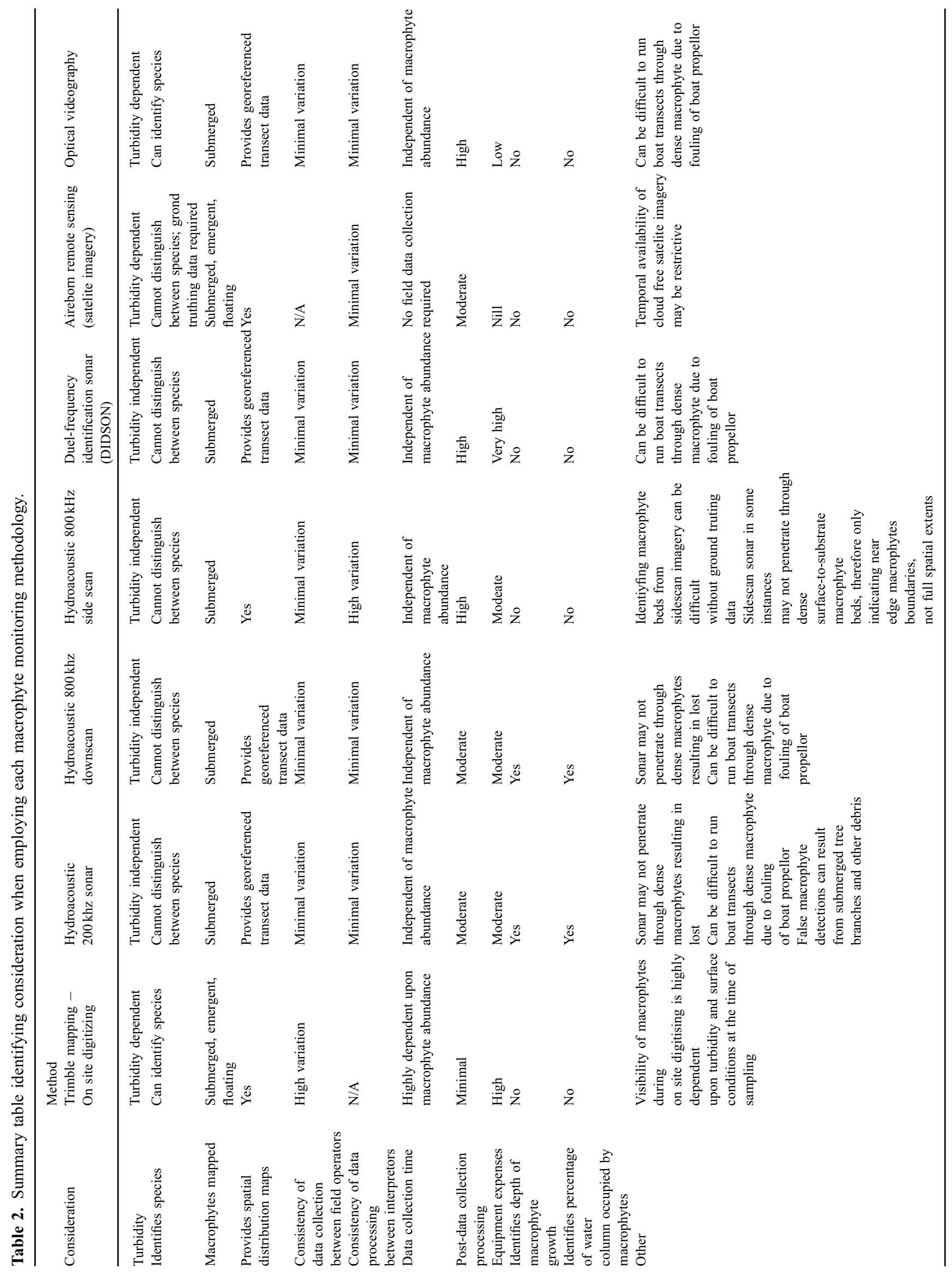


ground truthing data and allows for species identification, complementing the more spatially accurate and highly repeatable hydroacoustic $200 \mathrm{kHz}$ sonar and $800 \mathrm{kHz}$ downscan techniques.

Digitising macrophytes from airborne remotely sensed imagery provides the most cost-effective means to monitor macrophyte distribution over large spatial scales. No field data collection is required and high-resolution satellite imagery is available through a number of commercial sources. Airborne remotely sensed imagery provides a means to monitoring not only submerged macrophytes but also floating and emergent macrophytes. However, the monitoring of submerged macrophytes is turbidity dependent and ground truthing is required for discrimination between species.

This study outlines important considerations when selecting a methodology to be implemented in macrophyte monitoring studies (Tab. 2). Results indicate that no one specific method can be employed across all macrophytemonitoring studies. The method or combination of methods employed during macrophyte monitoring studies will be dependent upon the study objectives, budget and environmental conditions of the study site. Significant limitations were identified for all monitoring techniques assessed. However, these limitations may be of little concern depending upon the study objectives or can be overcome by implementing complementary methodologies. When species identity is important, such as when monitoring invasive aquatic vegetation, a combination of air-borne remote sensing and PDA Trimble mapping for species identification would provide an effective technique. However, when macrophyte PAC is the primary metric of interest, line transect hydroacoustic techniques including $200 \mathrm{kHz}$ sonar and $800 \mathrm{kHz}$ downscan sonar or DIDSON are the most applicable across a range of turbidities.

Acknowledgements. I thank New South Wales Fisheries personnel who provided technical advice and assistance, particularly Gregory West for satellite imagery data. We also thank Alec Davie from Water NSW for field assistance and providing access to the study sites. This study was funded by the Invasive Animals Cooperative Research Centre and New South Wales Department of Primary Industries, Fisheries NSW.

\section{References}

Bickers AN. 2003. Cost effective marine habitat mapping from small vessels using GIS, Sidescan Sonar and Video. In: Woodroffe CD, Furness RA, eds. Coastal GIS 2003: an integrated approach to Australian coastal issues. Wollongong.

BioSonics. 2019. Scientific Echosounders - Aquatic habitat echosounder. www.biosonicinc.com.

Boswell KM, Wilson MP, Cowan Jr JH. 2008. A semiautomated approach to estimating fish size, abundance, and behavior from dual-frequency identification sonar (DIDSON) data. North $\mathrm{Am} J$ Fisheries Manage 28: 799-807.

Boys CA, Robinson W, Baumgartner LJ, Rampano B, Lowry M. 2013. Influence of approach velocity and mesh size on the entrainment and contact of a lowland river fish assemblage at a screened irrigation pump. PloS One 8: e67026.

Caraco NF, Cole JJ. 2002. Contrasting impacts of a native and alien macrophyte on dissolved oxygen in a large river. Ecol Appl 12: 1496-1509.
Choi J-Y, Jeong K-S, La G-H, Joo G-J. 2014. Effect of removal of free-floating macrophytes on zooplankton habitat in shallow wetland. Knowledge Manage Aquatic Ecosyst 11.

Christia C, Papastergiadou E, Papatheodorou G, Geraga M, Papadakis E. 2014. Seasonal and spatial variations of water quality, substrate and aquatic macrophytes based on side scan sonar, in an eastern Mediterranean lagoon (Kaiafas, Ionian Sea). Environ Earth Sci 71: 3543-3558.

CMAP. 2018. Transforming high resolution satellite imagery of shallow bodies of water into detailed habitat maps. In: BioBase, ed. Minneapolis: CMAP BioBase.

Creese RG, Glasby TM, West G, Gallen C. 2009. Mapping the habitats of NSW estuaries. In: NSW II, ed. Fisheries Final Report Series. Port Stephens: Port Stephens Fisheries Institute.

Everitt JH, Yang C, Escobar DE, Webster CF, Lonard RI, Davis MR. 1999. Using remote sensing and spatial information technologies to detect and map two aquatic macrophytes. $J$ Aquatic Plant Manage 37: 71-80.

Genkai-Kato M, Carpenter SR. 2005. Eutrophication due to phosphorus recycling in relation to lake morphometry, temperature, and macrophytes. Ecology 86: 210-219.

Havens KE, Harwell MC, Brady MA, Sharfstein B, East TL, Rodusky AJ, Anson D, Maki RP. 2002. Large-scale mapping and predictive modeling of submerged aquatic vegetation in a shallow eutrophic lake. Sci World J 2: 949-965.

Holmes JA, Cronkite GM, Enzenhofer HJ, Mulligan TJ. 2006. Accuracy and precision of fish-count data from a "dual-frequency identification sonar" (DIDSON) imaging system. ICES J Marine Sci 63: 543-555.

Johnson JA, Newman RM. 2011. A comparison of two methods for sampling biomass of aquatic plants. J Aquatic Plant Manage 49: 1-8.

Kaeser AJ, Litts TL. 2010. A novel technique for mapping habitat in navigable streams using low-cost side scan sonar. Fisheries 35: 163-174.

Kaeser AJ, Litts TL. 2013. An illustrated guide to low-cost, side scan sonar habitat mapping. Panama City: United States Fish and Wildlife Service.

Kaeser AJ, Litts TL, Tracy TW. 2013. Using low-cost side-scan sonar for benthic mapping throughout the lower Flint River, Georgia, USA. River Res Appl 29: 634-644.

Kelly DJ, Hawes I. 2005. Effects of invasive macrophytes on littoralzone productivity and foodweb dynamics in a New Zealand highcountry lake. J North Am Benthol Soc 24: 300-320.

Kruss A, Tegowski J, Blondel P. 2009. Estimation of macrophytes using single and multibeam echo sounders and sidescan sonar in Arctic fjords (Hornsund and Kongsfjord, West Svalbard). Proceedings of 3rd International Conference and Exhibition on Underwater Acoustic Measurements: Technologies \& Results.

Lacoul P, Freedman B. 2006. Environmental influences on aquatic plants in freshwater ecosystems. Environ Rev 14: 89-136.

Langkau M. 2018. Echoes in motion: an acoustic camera (DIDSON) as a monitoring tool in applied freshwater ecology. University of Cologne, Cologne: Faculty of Mathematics and Natural Sciences.

Madsen JD. 1999. Point intercept and line intercept methods for aquatic plant management. Vicksburg MS: Army Engineer Waterways Experiment Station.

Mizuno K, Asada A. 2014. Three dimensional mapping of aquatic plants at shallow lakes using $1.8 \mathrm{MHz}$ high-resolution acoustic imaging sonar and image processing technology. Ultrasonics Symposium (IUS), 2014 IEEE International. IEEE, 1384-1387.

Mizuno K, Asada A, Ban S, Uehara Y, Ishida T, Okuda N. 2018. Validation of a high-resolution acoustic imaging sonar method by 
estimating the biomass of submerged plants in shallow water. Ecol Inform 46: 179-184.

Mizuno K, Xu C, Asada A, Abukawa K, Yamamuro M. 2013. Species classification of submerged aquatic plants using acoustic images in shallow lakes. Underwater Technology Symposium (UT), 2013 IEEE International. IEEE, 1-5.

Moursund RA, Carlson TJ, Peters RD. 2003. A fisheries application of a dual-frequency identification sonar acoustic camera. ICES J Marine Sci 60: 678-683.

Netherland MD, Jones KD. 2015. A three-year evaluation of triclopyr for selective whole-bay management of Eurasian watermilfoil on Lake Minnetonka, Minnesota. Lake Reservoir Manage 31: 306-323.

Radomski P, Holbrook B. 2015. A comparison of two hydroacoustic methods for estimating submerged macrophyte distribution and abundance: a cautionary note. J Aquatic Plant Manage 53: 151-159.

Sabol BM, Melton RE, Chamberlain R, Doering P, Haunert K. 2002. Evaluation of a digital echo sounder system for detection of submersed aquatic vegetation. Estuaries 25: 133-141.

Sainty GR, Jacobs SW. 2003. Waterplants in Australia. Potts Point, NSW: Sainty and Associates Pty Ltd.

Skogerboe JG, Poovey AG, Getsinger KD, Crowell W, Macbeth E. 2008. Earlyseason, low-dose applications of endothall to selectively control curlyleaf pondweed in Minnesota lakes. US Army Engineer Research and Development Center. 2019. Vicksburg (MS): APCRP Technical Notes Collection.

SoundMetrics. 2008. Dual-frequency identification sonar DIDSON Operation Handbook. Bellevue WA: Sound Metrics Corporation. Szoszkiewicz K, Ciecierska H, Kolada A, Schneider SC, Szwabińska M, Ruszczyńska J. 2014. Parameters structuring macrophyte communities in rivers and lakes - results from a case study in North-Central Poland. Knowledge Manage Aquatic Ecosyst 08

Valley RD, Johnson MB, Dustin DL, Jones KD, Lauenstein MR, Nawrocki JJ. 2015. Combining hydroacoustic and point-intercept survey methods to assess aquatic plant species abundance patterns and community dominance. J Aquatic Plant Manage 53: $121-129$

Xu C, Mizuno K, Asada A, Abukawa K, Yamamuro M. 2013. 3Dview generation and species classification of aquatic plants using acoustic images. J Marine Acoustics Soc Jpn 40: 14-26.

Yu J, Zhen W, Guan B, Zhong P, Jeppesen E, Liu Z. 2016. Dominance of Myriophyllum spicatum in submerged macrophyte communities associated with grass carp. Knowledge Manage Aquatic Ecosyst 24.

Zhang C, Boyle KJ. 2010. The effect of an aquatic invasive species (Eurasian watermilfoil) on lakefront property values. Ecol Econom 70: 394-404.

Cite this article as: Stocks JR, Rodgers MP, Pera JB, Gilligan DM. 2019. Monitoring aquatic plants: An evaluation of hydroacoustic, on-site digitising and airborne remote sensing techniques. Knowl. Manag. Aquat. Ecosyst., 420, 27. 